Entropy 2006, 8[2], 110-112

Entropy

ISSN 1099-4300

www.mdpi.org/entropy/

Editorial

\title{
Editor-in-Chief's Report
}

\section{Michel Petitjean}

ITODYS (CNRS, Université Paris 7, UMR 7086), 1 rue Guy de la Brosse, 75005 Paris, France E-mail: petitjean@itodys.jussieu.fr

URL: http://petitjeanmichel.free.fr/itoweb.petitjean.html

Received: 2 May 2006 / Accepted: 2 June 2006 / Published: 14 June 2006

Entropy has been launched in 1999 by Dr. Shu-Kun Lin, and it is now in its eigth year. Dr. Lin was the first Editor-in-Chief, and is the representative of the organization publishing the Journal. In January 2003, Dr. Lin introduced me in the Editorial Board of Entropy. Then, at the end of July 2003, Dr. Lin nominated me Editor-in-Chief of Entropy. It was a great honor for me to have been the successor of Dr. Lin, and I am highly indebted to him to have proposed me to edit Entropy.

The Journal scope focusses around any of the entropy concepts. They are of course found in thermodynamics and information theory, but papers dealing with entropy appear in various areas such as: probability, computer sciences, quantum mechanics, astrophysics, mechanical engineering, energetics, thermochemistry, thermobiology, bioenergetics, econophysics, and philosophy of science (this list is not exhaustive). So, it has been a constant challenge to edit such a pluridisciplinary journal. I never could have faced to this exciting task without the efficient help of the Associate Editors and of all the members of the Board, and I am highly grateful to them for the work they have done.

Entropy cannot be fully understand without realizing that it is an electronic Journal in Open Access. The scientific policy is to publish papers only on the basis of their scientific quality, so that we prefer to publish few papers rather than accepting numerous papers of doubtful quality. Since its creation, Entropy is an Open Acess Journal, so that any reader can download and read the papers for free. But, just as any product, a journal has a cost. Until August 2004, the cost was covered by a page charge of 500 USD, paid by the authors on a voluntary basis.

Publishing a journal in Open Acess which accepts only a limited number of papers cannot generate much money. It is why, in August 2004, I asked to Dr. Lin to suppress the page charge. 
So, Entropy is a fully free Journal since two years. The counterpart is that the authors produce themselves their papers in final form in PDF format without help from the publisher [1].

As long as Entropy publishes few papers, it is indeed possible to edit and publish Entropy without financial difficulties. On the other hand, the number of papers yearly published in ordinary issues $(13,14$, and 20 for the three successive July-June periods) has been increasing since I became the Editor-in-chief. The number of submitted papers has increased too, the ratio submitted/accepted being roughly constant along these three years.

All manuscripts submitted to Entropy must be anonymously peer reviewed. Apart a very limited number of manuscripts rejected immediatly due to an obvious poor quality, all the manuscripts that I have processed were indeed anonymously peer reviewed. The rule applies to the board members, to the associate editors and to the editor in chief, so that even my own papers $[2,3]$ have been anonymously peer reviewed. For the editor in chief papers, the reviewing process is managed by an associate editor. A consequence of the anonymous peer review rule is that the rejection may occur for any member of the Journal staff.

I never invited authors nor edited conference proceedings in Entropy. The special issues were edited by an associate editor [4] or by guest editors members of the board [5], and were launched at the initiative of Dr. Lin several months before I became the editor in chief. It means that the Journal may survive with spontaneous submissions. Having a fully free Journal has not been damageable, because the the ratio rejected/accepted has not increased during these three years. This ratio is about $3 / 2$. Some authors submit two papers at a time, but rarely more (it happened that an author had submitted 7 papers within 9 days; none was published).

I have done various minor changes in the Journal, such as the systematic use of the PDF format at the submission stage, the use of PACS codes and MSC 2000 codes, the creation of the "Letter to the Editor" category of papers, the restructuration of the web site, the cleaning and the parametrization of the html files, etc. However, I never used an electronic submission system, in order to have the best possible personal dialog with authors and reviewers. Some work remains to do, such as establishing more rules for the management of the Journal.

To conclude this editorial, I would say that a scientific Journal is not an ordinary product. It is the result of the work of the entire journal staff and board, the authors, the reviewers, and it cannot have sense without the readers. It is why the Open Acess merits to be held.

With this report, I would like to hand over my editorial work to the new Editor-in-Chief of Entropy. I strongly hope and wish that Entropy will continue to prosper in the future as a successful journal. 
Acknowledgments: I thank Ehsan Soofi, Associate Editor of Entropy, to have managed the review of this editorial, and I thank Dr. Shu-Kun Lin for having read and commented it.

\section{References and notes}

[1] In addition, I have accepted to earn no money from the publisher during all time I am the editor in chief. It means that the cost of the Journal is mainly my time.

[2] M. Petitjean

Chirality and Symmetry Measures: A Transdisciplinary Review

Entropy 2003, 5[3], 271-312

http://www.mdpi.org/entropy/htm/e5030271.htm

http://www.mdpi.org/entropy/papers/e5030271.pdf

[3] M. Petitjean

Editorial: The FIS2005 Conference in Paris

Entropy 2005, 7[3], 188-189

http://www.mdpi.org/entropy/htm/e7030188.htm

http://www.mdpi.org/entropy/papers/e7030188.pdf

[4] I. Dincer

Editorial: Special Issue: Entropy Generation on Thermal Systems and Processes

Entropy 2003, 5[5], 357

http://www.mdpi.org/entropy/htm/e5050357.htm

http://www.mdpi.org/entropy/papers/e5050357.pdf

[5] A.V. Nikulov and D.P. Sheehan

Special Issue on Quantum Limits to the Second Law of Thermodynamics

Editorial: The Second Law Mystique

Entropy 2004, 6[1], 1-10

http://www.mdpi.org/entropy/htm/e6010001.htm

http://www.mdpi.org/entropy/papers/e6010001.pdf

(C)2006 by MDPI (http://www.mdpi.org). Reproduction for noncommercial purposes permitted. 